\title{
Materiality of body, materiality of world - remarks on emancipatory education: Illich, Freire and contemporary political philosophy
}

\author{
Urszula ZBRZEŹNIAK*
}

\begin{abstract}
The paper addresses the issue of the corporeal dimension of the learning process. The problem of the material side of education has emerged within the emancipatory education project, but, as will be argued, this was limited to a critique inspired by Marxist tradition. The perspective on the materiality of education offered by Freire's and Illich's works can be significantly enriched by contemporary political thought. The latter perceives materiality in its complexity, that is, as economic conditions but also as the inherent needs stemming from our bodily condition. As will be demonstrated, the contemporary reflection could serve as a critique, one on the limited character of Freire's and Illich's emancipatory education, as well as providing ideas which might expand their project.
\end{abstract}

KEYWORDS

body; material condition; emancipation; Paulo Freire; Ivan Illich

* PhD. (habil.), assistant professor, Department of Philosophy, University of Warsaw. E-mail: urszulazbrzezniak@uw.edu.pl. 
When one thinks about education one, usually, focuses on intellectual capacities; and here regardless of whether we think of it as a mere transmission of information or as the process of acquiring knowledge accompanied by the transferral of a specific attitude towards others and the world. Regardless of how education is apprehended, it seems that the place and function of the body are being ignored or at least underestimated by philosophers writing on education. This omission of the bodily dimension within the learning process is even more significant among contemporary thinkers attempting to redefine the traditional type of education and opening institutional order to new forms of learning. ${ }^{1}$

This paper addresses the contemporary concept of education, aiming at the fundamental reconstruction of the existing model of learning in the perspective of the above mentioned exclusion of the problem of the body and not recognizing it as a significant component of education. The overlooking of the theme of the bodily aspect in the learning process is difficult to understand and to explain when compared to the constant and growing interest in the corporeal dimension of man in present-day thought. The first part of the paper will address the limitations of the emancipatory education projects developed by Paulo Freire and Ivan Illich, ones which still inspire many intellectual currents and education theoreticians. ${ }^{2}$

Although Freire and Illich place the liberation, the emancipation of individuals, at the centre of their education programs issues concerning the bodily condition of education seem to play a secondary role in their reflections. Hence, one may ask if this omission of the corporeal aspect of education does not lead to unpredictable or even unwanted results? In the following paragraphs, various emancipatory theories of learning will be examined regarding the question of the body understood as the necessary background and independent source of sense in the learning process.

1 Jacques Rancière might be an excellent example of just such a philosopher. In his book on the experimental educational practice of Joseph Jacotot in Ignorant schoolmaster (Rancière, 1991), he provides a different model understanding of pedagogy that breaks with the traditional representation of the teacher-student relation. True education in Jacotot's and Rancière's understanding leads to student emancipation. However, the latter does not operate through the transmission of knowledge but through self-education. A teacher in Jacotots's and Rancière's project only incites students to learn but does not impose any knowledge. This quite unusual concept of education has been widely discussed by theoreticians of education (Biesta, 2010; Lewis, 2012) thus confirming its importance. Despite its truly revolutionary character Rancière's concept of emancipatory education is bereft of any deeper reflection upon the material conditions for a such education.

2 Suffice it to mention the whole strand of critical pedagogy represented by bell hooks, Henry Giroux, Peter McLaren or Stanley Aronowitz — to name but a few — to realize how profoundly Freire's thought significantly influences present-day critical discourse on education 


\section{CULTURE AS A TRAINING OF THE BODY}

The problem of the bodily aspects of education, especially for philosophers, has always been to some extent secondary. ${ }^{3}$ In that regard, many philosophers have not disentangled themselves from the Platonic perspective privileging the mind and depreciating the body - an earthly vehicle of the eternal soul. And yet the body, even within ancient tradition, has marked its presence by the constant emergence of desires and drives, and by the necessity of a training which inscribes the body into the cultural, social order. Therefore, any subjugation of the body seems to be an inherent trait of culture as such. From Plato through Immanuel Kant and Friedrich Nietzsche the body appears as the surface of inscription, as the raw material to be formed. As Nietzsche and Michel Foucault pointed out, our civilisation is the project of the self-transformation of man, in other words, the ongoing effort to subjugate natural needs and desires to a project called "man". Nietzsche in The genealogy of morals reveals a vision very similar to that presented by Kant in Lectures on pedagogy, namely man must create himself by effort, by imposing on himself discipline and by suppressing all natural/animal tendencies (Nietzsche, 1989: 59; Kant, 2007: 438). Culture, hence, presumes training, discipline or as Foucault said here echoing Nietzsche, every culture develops some forms of askesis, i.e., forms of self-training (Foucault, 1990: 27). Very recently, a remarkably similar perspective was adopted by Peter Sloderdijk. In You must change your life he explores this core program of human life. The latter is conceived as the "pontifical" by essence, which means that the vocation of human life lies in the ability to create the crossings, the connections "between the bridgeheads in the bodily realm and those in cultural programmes" (Sloterdijk, 2013: 11).

From the outset, philosophy has set out to convince one that human life requires the sacrifice of our inferior functions. In other words, philosophy emerges as the discourse centred around a project of establishing the proper hierarchy within man. Thus, the body is apprehended as, by definition, passive, and a merely accidental foundation of human intellectual activity. However, as was mentioned above, the body disciplined and subjugated was apprehended as a sort of constant threat to the fragile order that culture creates and recreates.

Contrary to the traditional dualistic view of the body, some significant philosophical currents began to explore the inherent activity of the body, and thus laid the foundation for the ontology of the living body. From Maurice Merleau-Ponty, who initiated this type of analysis of corporeality, to Foucault, who developed a critical analysis of the modes of subjugating the body, we see

${ }^{3}$ This thesis quite clearly is true when we talk about dominant tendencies in Western culture. From the very beginning there was a materialistic strand within philosophy, though its role was rather minor. 
expansion of the reflection focused on the body. ${ }^{4}$ What merits notice is the general trend inaugurated by those two philosophers who belong to different traditions. Both share the same goal, that is, they try to surpass the objectifying mode of apprehending the body. ${ }^{5}$ Merleau-Ponty proposes a completely new understanding of the human body, one taking into account its dynamic character. The latter should be understood in a broader sense: as the natural mobility of the body, but also as the active interrelation of the body and the world. However, whereas Merleau-Ponty was more interested in building a positive ontology of the embodied subject, Foucault was prone to view the same active and labile relation between the world and an individual immersed in that world through the genealogical lens. Although, it should be noticed that he left some indications that he perceived the living body as the potential source of resistance (Foucault, 1998: 157). Unfortunately, except for some remarks given in interviews Foucault has never developed this theme of a "different economy of bodies and pleasures" and its possible impact of the institutional order. As a result, it is impossible to say, if Foucault thought that it was possible to reform the institution of school or whether as a result of disciplinary order it was doomed to reproduce disciplinary and normative power relations. ${ }^{6}$

The problem of the living body brought to the forefront of contemporary philosophy was allowed to rethink and criticise a philosophical tendency, to forget the bodily condition or at least to view it as a minor factor. In the thought of Merleau-Ponty and Foucault the body remerges not only as passive material, but as a potentially meaningful layer. Thus, the most urgent task is to unveil this hidden potential. The type of body problematization present in Merlaeu-Ponty's and Foucault's philosophy indicates a very problematic point within contemporary reflection on the body. The latter is apprehended in a dual character, that is, the body as an "inscribed surface of events" (Foucault, 1980: 148). However, at the same time the body is conceived as the potential space of counter-power. The same ambivalence of body, but also of the subject of emancipation reappears, both, in critical reflection on education and

${ }^{4}$ Unfortunately, I am not able to address all the thinkers and currents that have developed a critical reflection on this subject. Suffice it to mention that the living body as a departure point for philosophical reflection appears in new materialism within contemporary feminist thought, or new materialism influenced by Baruch Spinoza or, to be more precise, influenced by the Deleuzian reinterpretation of Spinoza's materialism.

${ }^{5}$ Merleau-Ponty very clearly claims that any objectifying approach leads to insurmountable difficulties (Merleau-Ponty, 2002: 12). And Foucault from his early book The birth of clinic to the first volume of The bistory of sexuality writes a history of this objectification of the human body.

${ }^{6}$ One may argue that although his works on disciplinary and normative power do not permit such a positive reflection on the possible reform of school, his works on the care of the self do bring a new problematisation to the master-student relation and therein do open up a way to rethink and remodel education and school (Ball, 2017). 
contemporary political philosophy. The status of the body, hence, turns out to be one of the most fragile points within critical reflection on education and politics.

\section{WHO IS THE SUBJECT OF EMANCIPATION?}

One of the undeniable merits of a critical reflection on pedagogy was the significant change in the perception of the school system and the hidden logic supporting the said. Some may argue that this type of critical reflection has a long tradition in philosophy, as well as in pedagogy. However, Freire and Illich - not to mention Rancière - have modified our view on the role of education to such an extent that is it impossible to think about the latter without at least referring to their critical perspective. Moreover, both, Freire and Illich have disclosed a significant connection between education and politics. As Freire points out there is no neutral education because the latter, along with politics, reflects or rather expresses human nature (Freire, 2001: 47, 80). As a result, their analysis combines two aims: a critical reflection on existing education and a positive project of emancipatory education. In sum, although every education is political, not every educational policy leads to desirable from Illich's and Freire's perspective - goals.

While analysing arguments against the traditional method of learning developed by Freire, Illich is surprisingly accurate and can still provide a basis for a critique of present-day education. Nonetheless, it is very surprising that Freire's and Illich's works lack any deeper reflection on the positive ontology of the body. And yet they assume some form of anthropological reflection including an ontology of the living body as such.

A closer analysis of the main works of the mentioned authors shows their very visible indebtedness to classical Marxist analysis of the hidden logic of institutions. Freire admits later that his point of view presented in The pedagogy of the oppressed (Freire, 2005) was inspired by Marxist and the existentialist tradition (Freire, 2019: 11), and it seems that in his late works he was still influenced by this tradition. In Pedagogy of hope, which is a sort of critical reflection on Pedagogy of the oppressed, Freire claims that although we experience various forms of discrimination in the last instance it is the class conflict that causes and permeates other forms of discrimination (Freire, 2019: 146). Freire explicitly points to class as an economic basis of discrimination. This emphasis explains why his perspective fuels various forms of critical reflection on contemporary education. Moreover, Freire remarked on the danger of neoliberalism in its economic as well as ideological function (Freire, 2001: 35, 94), and unveiled the economic goals standing behind the ethical discourse accompanying globalisation (Freire, 2001: 94). 
As already mentioned Freire and Illich start from a critical analysis of the contemporary schooling system. This critical "phenomenology of school" (Illich, 1970: 25), to use Illich's expression, comprehends school as the main factor in the implementation of social structure, that is a system of power and economic relations accompanied by a specific form of culture (Freire, 2005: 74). Illich, long before Freire, acknowledged that the hidden curriculum determining the "substance" is a matter of the almost universal structure of domination permeating every school system regardless of its national identity (Illich, 1970: 74). Despite using quite a different terminology, Freire and Illich attempt to grasp the nature and dynamic of the hidden curriculum moulding the educational system and recreating the power relations through the process of the formation of students.

The visible impact of the Marxist tradition in Illich's and Freire's stances takes a very visible form of the "genealogy" of the modern school. They both are interested in unveiling the hidden agenda, political rationality transmitted within the scholar system that usually presents itself as an incarnation of meritocracy. It is difficult to reject this thesis, especially when we place Freire's and Illich's works in the broader context of after-war critical theory and especially the perspective presented by Jürgen Habermas in Technology and science as "ideology" (Habermas, 1970).

Freire in Pedagogy of the oppressed elaborates a concept that later will be termed "historico-cultural, political psychoanalysis" (Freire, 2019: 46), that is, an explanation of the dynamics supporting the existing socio-economical order and the function of education within this order. Similarly to Freud's project, Freire builds an explanation of the internal dynamic along with a particular form of therapy, in this case his concept of liberatory emancipation. It is worth noting that both Freire and Illich use the notion of alienation to describe the role and consequences of contemporary schooling and at the same time to indicate the aim of their critical reflection, namely, a desalienation of individuals carried out through a new form of schooling.

Freire in Pedagogy of the oppressed developed an interesting but also quite problematic model of desalienation as a form of reeducation of individuals. A reeducation that, as Freire underlies, is not imposed on those individuals by an educator, but rather established with them through the process of mutual discovery (Freire, 2005: 96). However, despite all of Freire's reservations it is questionable whether his concept of liberatory education does not imply some form of paternalistic attitude. Freire himself was aware of this type of objection (Freire, 2019: 56), but the way he replied indicates that he was not able to grasp the more radical stances, especially those emphasising the uniqueness of certain experiences or perspectives. That explains why bell hooks, who is deeply influenced by Freire, admits that he was unable to recognise some fundamental limitations of his standpoint. hooks points out that Freire, along with other 
critical thinkers and activists of his generation, was unaware of the fact that the type of liberation they advocate represents a "phallocentric paradigm" (hooks, 1993: 148). Perhaps, this unconscious perspective is responsible for Freire's inability to transgress a universalist perspective which presumes that finally there is a common denominator for different experiences (Freire, 2019: 141). Perhaps, behind the emphasis put by Freire on the unity established above all differences, stands an unknowing tendency to privilege the intellectual dimension. After all, as he reminds us, this "unity in diversity" is not a natural trait but a project (Freire, 2019: 147). While hooks chooses a different path: she focuses on the particularity of our situation (as this embodied subject who can neither escape nor disregard their condition) and uses it as a departure point for her reflections. ${ }^{7}$

Freire very often speaks of experience creating a specific form of representation of the world, that is, a unique experience connected to a particular place, socio-economic milieu. Moreover, he even develops a very interesting reflection on the forms of life and politics stemming from a such unique perspective, ${ }^{8}$ and yet his reflection obliterates the possible subversive potential of this bodily condition of human existence. Freire sees the differences and values them, but still puts emphasis on what should be a common, shared identity.

Illich seems to offer even deeper insights into the complexity of power relations, which may impact the process of learning to a greater extent than Freire's theory does. His remarks concerning the triple function of the teacher who gathers and executes power exceed the analysis of the classroom from Discipline and punishment (Illich, 1970: 37). ${ }^{9}$ However, despite all the brilliant insights brought by his reflection, the body, the specific place of the body, somehow escapes his attention. Although Illich devoted one of his texts to the problem of the body, and more precisely, to the problem of sexuality and its political meaning concerning sexuality, this is rather traditional (Illich, 1980: 115-128).

${ }^{7}$ One of the best examples of such a practice is her essay on passion, sexuality and pedagogical relation. Quite clearly she returns to the classical, Platonic theme of the erotic dimension in the pedagogical relation. But she approaches this question from a very particular point of view and uses this particularity to shed new light of the problem (hooks, 2003: 139-155).

${ }^{8}$ One of the most beautiful illustrations of this connection is the example of difference between two Brazilian communities with which Freire worked: the inhabitants of Recife and the fishing community (Freire, 2019: 13).

${ }^{9}$ Illich very accurately grasps the normative role of the contemporary teacher who, apart from being the representative of a particular cultural and social model, assumes a therapeutic function grounded in the continuous surveillance and unimpeded access to the life of the students. What makes this depiction strikingly accurate, is the combination of the legal and medical function of the teacher. And as the reader familiar with Foucault's genealogy of modern society knows, the overlapping of hitherto independent powers and functions constitutes his main thesis on the nature of this society. 
He encourages us to establish personal autonomy through the application of a certain regime to our body and its needs. As he points out, political actions should not be separated from the individual responsibility of a parent (Illich, 1976: 127)..$^{10}$ So, what we see here is a sort of isomorphism between private and public life. However, he does not suggest that the role taken in private life could in some respect impact on the public sphere.

The limitation of the problematics concerning the carnal condition in relation to human sexuality is here typical not only for Illich but probably all representatives of critical pedagogy. In Illich's case addressing the problem of human sexuality as an issue concerning parenthood discloses a tendency to repeat a rather traditional perspective on the bodily sphere. It is worth reminding oneself the import of Illich's essay, which was to unveil the political potential hidden within the sexual sphere. Needless to say his analysis not only brought to the surface the relation of power impacting the existing discourse on human sexuality and the diverse strategies of using the latter, but along with this critical perspective, it develops some ideas for taking control over this sphere of human life. The solutions proposed by Illich stem from the ideal of personal autonomy which seems to occupy the central place in his anthropology, as well as in his political thought. On the one hand, the ideal of personal autonomy and responsibility advocated by Illich is very compelling, but the traditional mode of apprehending sexual identities, result in a rather conservative model of society. Perhaps, Illich expresses here, in his unique way, his adherence to the tradition of the Enlightenment.

One can assume that the anthropology, along with a normative vision supporting his arguments, stems from the double intellectual heritage: the leftist tradition and Christianity. The presence of the strong assertions concerning human nature and the vocation of the community is most apparent in Illich's texts but is treated as a sort of background that does not require any further explication.

Paulo Freire's writings not only present a very similar perspective on the nature of community and the vocation of the individual but also in a very similar way avoid any direct discussion concerning the normative foundations supporting his claims. Freire in his late writings admits that his previous works imply anthropology but does not reveal the main presuppositions of this anthropology. This theoretical lack may probably be explained by the specific atmosphere of that epoch. The leftist thought of that time was influenced by various trends. Both Freire and Illich focus more on developing their practical ideas and examining economic and social trends than on legitimising their discourse.

${ }^{10}$ The limitation of the body problems to those concerning natality and fertility control is quite significant. The reader should nonetheless bear in mind the social, cultural, and in Illich's case also the religious context of his stance. 
They both were above all practitioners, thus the problem of theoretical coherence is rather a minor issue.

The problematization of the body present in Freire's and Illich's thought is also very problematic, not only from an academic perspective but also from a practical point of view. As Sherry Shapiro has rightfully remarked, critical pedagogy - and the same could be said about Freire's and Illich's thought places so much attention on the examination of the ideological and economic structure impacting the field of education, that they fail to recognise "the body knowledge" (Shapiro, 1991: 21). ${ }^{11}$ By that she means the tacit knowledge of the body which requires emancipation as does our mind. Shapiro's point of view enables one to grasp and fill in the blind spots of a critical pedagogy centred around the themes of those ideological frames shaping everyday perception as well as questions concerning the most vital economic domination tacitly shaping this reality. Her very friendly commentary plots a way to open or to expand the horizons of critical pedagogy and allows one to articulate the problem of living experience and its formative function. The critical work done by Freire and Illich, and by the generation of critical pedagogues, is interested in an analysis of the institutional and ideological influences shaping our lives and perception of the world. And while the material side is of great importance for that type of critical thinking, it is highly doubtful whether this reflection allows one to discover the truly emancipatory function of the body itself. Freire's and Illich's work rather prove that the type of reflection inspired mainly by Marxist tradition, is prone to apprehend the body, and the question of materiality of the human world, in a very narrow sense. ${ }^{12}$

For Freire and Illich materiality, including the issues concerning the human body, seem to be perceived in a dualistic way: either they pose an obstacle, or they support human development. This approach to the problem of material conditions stems directly from the Marxist tradition that Freire and Illich are both indebted to. However, what seems to be missing from their depiction, is the internal logic of technique, to the materiality, and at least to the body itself. This tendency might be explained as a consequence of the implicit dualism typical of the critical pedagogy described by Shapiro (Shapiro, 1991: 17). Moreover, Shapiro mentions that the perspective of critical pedagogy should be complemented by a reflection concerning the question of the dual character of the body, i.e., the body as the realm of the application of various powers and as the basis for emancipation (Shapiro, 1991: 18).

${ }^{11}$ It is worth noting that Peter McLaren started to develop a similar perspective, one attempting to incorporate bodily experiences (Cruz \& McLaren, 2002).

12 bell hooks in her book on the pedagogy of hope is a perfect example of the other way of problematizing the body, emotions, and shows - and here crucial given the perspective of this paper - how to translate the reflection on these problem into a positive program of social change (hooks, 2003). 
The ambivalence of the body as emphasised by Shapiro provides an interesting perspective on its possible role in education. Moreover, her stance offers a strikingly similar point of view to that presented by Judith Butler in the Psycbic life of power. Although Butler's analysis focuses on the strange function of the internalisation of external power as the crucial element in the constitution of the subject, it also addresses the question whereby the subject, as the effect of a power relation, can become an active subject, or precisely speaking, the subject of power. What seems to be the most important point in Butler's argument is the unavoidable duality constitutive of the subject (Butler, 1997: 15). Butler manages to grasp the point of the complete indifference between the external influence shaping an individual and auto-determination. It is interesting that both questions are indeed closely related, due to their fundamental relation to the subject's constitution. For, regardless of the nature of the power, the creation of the subject requires the imposition of power on the body (Butler, 1997: 36). The body remains this silent object for the inscriptions of the effects of power and yet, as the main aim of power, it still retains a transgressive potential. The question thus appears: what role should emancipatory education ascribe to the body as the virtual place of liberation?

As was mentioned, the materiality of education did not escape Freire and Illich, yet their reflection on the matter was to some extent limited. One could even argue that some of the revolutionary ideas concerning the new forms of social and educational interaction are lacking in a vital element, a new representation of the individual and the social body.

Freire points out that the traditional system of education is insensitive to the material conditions of learning in many forms. Traditional education or, as Freire and Illich would say, an education supporting the existing social order, does not provide enough material resources for a good education. But apart from the problem of chronic underinvestment in public education, Freire and Illich disclose a strategic blindness to the conditions of student life (Freire \& Macedo, 2005: 107). One could argue that along with the construction of the school program the presumed requirements an average student should meet function as a mechanism for the elimination of individuals from the school system (Freire \& Macedo, 2005: 85; Illich, 1980: 97). The program of universal teaching may be criticized because of its ideological function that solidifies the existing order by the direct transmission of knowledge, and by operating as a specific rite de passage, which constitutes the main operator of exclusion. ${ }^{13}$

${ }^{13}$ It is worth noting that Freire and Illich apprehend this strange function of universal education, which according to official rules should be a mechanism of inclusion, though in fact it operates as a mechanism of selection. Illich goes even further in his critique of universal schooling by showing that in certain circumstances the application of this model leads to a deepening of social divisions (Illich, 1980: 107). 
If one admits that the existing system of education distorts rather than improves society, then quite naturally the question as to its transformation arises. Freire in his theoretical and practical approach proves that such an amelioration is possible by remodeling existing schools and by introducing hitherto neglected forms of education (adult education). Illich presents a more radical attitude towards universal schooling, stressing the need for a new system of knowledge transformation to replace the school and to provide a system of knowledge and skill transference. Most innovative is the project for an extra-institutional system of mutual education developed in Deschooling society. His remarks on the possibility of establishing "learning webs" (Illich, 1970: 74) opens up the possibility of open, democratic and self-governed forms of education, where an individual is completely free in their choice of what and when they want to learn. Illich attempts to redefine all institutions involved in education into a "flat" structure that rather facilitates an exchange of information between individuals (those who learn and those who teach). And despite the truly innovative ideas within this "flat" structure of knowledge exchange, there is a significant gap in Illich's argumentation. And here the matter directly involves the body. Illich speaks about this new structure exclusively in terms of skills and knowledge exchange (Illich, 1970: 78-79).

Particularly interesting within this alternative structure of education is the innovative idea of education becoming a sort of ongoing activity transgressing the curriculum and transforming itself into a universal human need. ${ }^{14}$ Alongside the general idea of mutual education, Illich develops reflection on the technical conditions of this educational web. In this point, his project is extremely innovative, due to the tele-informatic web idea which Illich perceives as a necessary element in the web of knowledge exchange. In other words, a very particular infrastructure turns out to be the condition possibility for this democratic, open type of universal learning-teaching system. Illich focuses on the purely technical matters of the most accessible media serving as the channels for a more egalitarian instrument of knowledge and skill sharing.

In a paradoxical way contemporary political philosophy may shed new light and resolve some of the issues left by Freire and Illich. I would like to refer to the works of Judith Butler and Antonio Negri mentioned above. Butler will provide the necessary perspective, I hope, to complement Illich's ideas, while Negri develops some elements already present in Illich's concept of a new,

${ }^{14}$ It is legitimate to ask whether Illich's project should be read as the repetition of the Marxist idea of work (in this case education) as the realization of the essence of humankind. Freire speaks of the vocation of humanity in very similar terms, when it comes to determining the essence of man. In other words, we see in Illich's and Freire's works almost the same anthropology that identifies learning as man's vocation. 
horizontal structure of mutual education. ${ }^{15}$ Moreover, in Negri's perspective the bodily aspect of such a democratic, horizontal education emerges. This bodily aspect should be more accurately called a material aspect of education. Contrary to Illich, Negri, and here following on from Gilles Deleuze, placed emphasis on the emotions, the desire which transforms itself into the fundamental traits of a new community and new politics (Negri \& Hardt, 2009: 30, 38).

Despite the originality of Illich's approach to alternative learning webs, what is missing is finding unexpected supplementation through the recent writings of Negri. Illich presumes the constitution of the learning webs to have a tremendous impact on society as a whole (Illich, 1970: 73). What seems to have escaped his notice is the socio-cultural milieu in which such internal change could take place. Along with the technical means required for the institution of learning webs, the cultural revolution must take place in a very specific place, that is, in the city. Antonio Negri and Michael Hardt in their book on the morphology of future social and political change, show that the latter requires a metropolis, something much more than a specific space. The metropolis becomes a natural extension of human activity, or to be more specific, it transforms itself into an in-organic body of the multitude - a new revolutionary subject.

\section{THE POLITICS OF THE METROPOLIS, THE POLITICS OF THE BODY}

The concept of the metropolis is of great importance due to the direct bond established between an individual body and a material milieu enabling cultural, political and social transformations. The metropolis transforms into the elementary condition of human existence (Negri \& Hardt, 2009: 252). Apart from the technical support that such a metropolitan community requires, it seems crucial, for Illich, Negri and Hardt equally, that the new space is fundamentally the space of encounters (Negri \& Hard, 2009: 252).

Along with the question of the necessary political work that should be undertaken to transform the metropolis into a new community, into a polis (Negri \& Hardt, 2009: 254), is the issue of the bodily character of this new

15 That said some may object that Illich did not completely reject the idea of meritocracy and that his idea of an alternative system of distribution of knowledge and skills cannot be described as mutual education, due to the asymmetry of the knowledge presumed in this model. This objection is legitimized; however, it must be emphasized that Illich wanted to except his alternative model from the vertical structure of existing schooling. And for this reason his model diminishes the role of hierarchical relations in the process of learning. It is undeniable, though, that an asymmetry of knowledge or skills cannot be eradicated from the teaching-learning relation because every learning relation presumes just such an asymmetry. 
community. As mentioned earlier, Negri and Hardt, in following Deleuze, consciously blur the division between an individual body and its surroundings, and transform the latter into a sort of extended community body. Although the metaphor of the city as the inorganic body of the future community is quite attractive, for the sake of this paper I would like to stress the function of the individual body in the process of the constitution and development of the future community.

The analysis of the metropolis and the form of life proper to it underlines the role of encounter, that is, the possibility of creating new ideas through accidental meetings. As a result, the metropolis emerges as the topological structure that may enhance human inventiveness. The interesting point of Negri's and Hardt's analysis, which also marks its presence in Illich's perspective, is the essential role of physical contact in the process of creating new ideas, meanings. It turns out that the metropolis or the learning webs use technological support, but ultimately fundamental action requires the physical presence of individuals. Negri and Hardt very clearly indicate that carnal mediation is somehow the vital element unifying the new community.

A similar perspective on politics, topology and bodily presence appears in Butler's works. In her book on political topology, she highlights the indispensability of the bodily presence within the commune sphere. Politics in the last instance turns out to be rooted in the bodily condition of the acting subject. Bodily presence during politically significant events is a catalyst of identity emerging at that particular moment when individuals are gathering to discuss, fight, defend themselves. The body is not just a vehicle of a political subject, the body establishes political demands by its mere physical presence (Butler, 2015: 83). Butler in her reinterpretation of the classical depiction of politics in terms of the corporeal shows that the body, contrary to what political philosophy would presume, is to some extent an autonomous source of meaning (Butler, 2015: 71). The transformation of the point of view resulting from the incorporation of the body into the reflection on politics significantly modifies the crucial notions of that reflection. Butler mentions the division between the public and private, but one can argue that the inclusion of the bodily perspective globally changes the manner in which we comprehend the political.

Although Butler does not here invoke Merleau-Ponty's philosophy, it is legitimate to argue that her general view on the body-mind relation and concept of the body as the source of sense, is analogous to the idea of the meaning presented in Phenomenology of perception. Butler adopts a very similar approach to the fact that intellectual activity is rooted in and thus deeply impacted by the bodily condition. The latter ceased to be viewed as the mere basis on which higher, intellectual activity is built, and deploys its logics. The materiality of political action described by Butler takes into account not only the material 
conditions of the world, but also the dimension of bodily activity understood as "what the body can do" (Butler, 2015: 73). ${ }^{16}$

As a consequence, the body turns out to be an independent source of political demand and action, a distinct dimension of new ideas. Thus, it is clear that Butler not only undermines the traditional intellect-body distinction but also tends, to some extent, to reverse the hierarchy supporting that distinction. The body, its possibilities, needs, and most of all its vulnerable character becomes the main space of the political struggle.

\section{CONCLUSION}

The question thus remains: to what degree can contemporary reflection complement emancipatory education projects? One could argue that materiality and specific bodily needs are included in those projects, due to their leftist heritage. It is indisputable that Freire and Illich are extremely sensitive to material needs. Yet, one may argue that the historical situation to which they responded in their projects was different than that of the present-day world. Although Freire very early on acknowledged the danger of the neo-liberal order in its economic and ideological form, he did not fully recognize the potential and danger inherent to cognitive capitalism.

It seems that contemporary reflection on the conditions of future politics and society is developing some of the most important ideas adumbrated by Freire and Illich. The present-day analysis of the material and informatic foundation of any future community are compatible with some of their major presumptions. Moreover, the ideas of a democratic, "horizontal" community as developed by Negri and Hardt may be viewed as an epitome of the utopian hopes expressed by Illich and Freire. In sum, the contemporary political thought to some extent complements their educational and political reflection. However, it must be stressed that in the fundamental points, Freire's and Illich's work requires significant modification. The body and the traditional hierarchy between intellect and body presumed by Freire and Illich is one of these vital points in need of correction. One may even argue that the new approach to the body seeing it as the source of meaning, as the basis of political demands, deepens the vision of democracy permeating Freire's and Illich's thought.

${ }^{16}$ Even though the concept is a direct reference to Deleuze and Spinoza, very similar idea of the body as the sphere of potentiality one can find in Merleau-Ponty's thought under the name je peux. 


\section{BIBLIOGRAPHY}

Biesta, B. (2010). Jacques Rancière: Education, Truth, Emancipation. London-New York: Continuum.

Ball, S. (2017). Foucault as Educator. Cham: Springer.

Butler, J. (1997). The psychic life of power. Stanford: Stanford University Press.

Butler, J. (2015). Notes toward a performative theory of assembly. CambridgeLondon: Harvard University Press.

Cruz C. \& McLaren, P. (2002). Queer bodies and configurations: Toward a critical pedagogy of the body (pp. 187-207). In: Sh. Shapiro, M. College, \& S. Shapiro (Eds.). Body movements. Pedagogy, politics and social change. Cresskill: Hampton Press.

Foucault, M. (1980). Language, counter-memory, practice. (D.F. Bouchard \& S. Simon, Trans.). New York: Cornell University Press.

Foucault, M. (1990). The use of pleasure. (R. Hurley, Trans.). New York: Vintage Books.

Foucault, M. (1998). The will to knowledge. (R. Hurley, Trans.). New York: Vintage Books.

Freire, P. (2001). Pedagogy of freedom. Lanham: Rowman \& Littlefield.

Freire, P. (2005). Pedagogy of the oppressed. New York: Continuum.

Freire, P. (2019). Pedagogy of hope. London-New York: Bloomsbury.

Freire, P. \& Macedo, D. (2005). Literacy. Reading the word and the world. London: Routledge. Habermas, J. (1970), Technology and science as 'ideology' (pp. 81-122). In: J. Habermas, Toward a rational society. Student protest, science, and politics. (J. J. Shapiro, Trans.). Boston: Beacon Press.

hooks, b. (1993). bell hooks speaking about Paulo Freire. In: P. McLaren \& P. Leonard (Eds.). Paulo Freire. A critical encounter. New York: Routledge.

hooks, b. (2003). Teaching community. London-New York: Routledge.

Illich, I. (1970). Deschooling society. New York: Harper\&Row.

Illich, I. (1976). Celebration of awareness. New York: Penguin Books.

Kant, I. (2007). Antbropology, history, and education. (R. M. Louden \& G. Zöller, Ed. \& Trans.). Cambridge: Cambridge University Press.

Lewis. T. (2012). The aesthetics of education. London-New York: Continuum

Merleau-Ponty, M. (2002). Phenomenology of perception. (C. Smith, Trans.). London-New York: Routledge.

Negri, A. \& Hardt, M. (2009). Commonwealth. Cambridge: Harvard University Press.

Nietzsche, F. (1989). On the genealogy of morals. Ecce homo. (W. Kaufmann \& R.J. Hillingdale, Trans.). New York: Vintage Books.

Rancière, J. (1991). Ignorant schoolmaster. (K. Ross, Trans.). Stanford: Stanford University Press.

Shapiro, S. (1991). Pedagogy and the politics of the body. New York-London: Garland Publishing, Inc.

Sloterdijk, P. (2013). You must change your life. (W. Hoban, Trans.). Cambridge: Polity Press. 
